\title{
Participatory Video at the UN Global Migration Film Festival: engaging displaced indigenous Venezuelans in filmmaking
}

- Amanda Martínez Nero and Fernanda Baumhardt UN/IOM Global Migration Film Festival

$\left(\begin{array}{l}\text { Reception date: November 12, } 2019 \\ \text { Approval date: January 7, } 2020\end{array}\right)$

DOI: http://dx.doi.org/10.15304/ricd.3.11.6406

\section{BIOGRAPHY NOTES}

Amanda Martínez Nero is Communication Officer at UN/IOM, holding a bachelor in Social Communication and Journalism and a master degree in Humanitarian Action. As the Global Migration Film Festival coordinator she managed, co-designed and co-facilitated the participatory video project.

Contact: anero@iom.int

Fernanda Baumhardt is Humanitarian Communication with Communities specialist at NORCAP (Norwegian Refugee Council Capacity), holding a Bachelor in Social Communications and Journalism from the Brazilian Universidade do Vale do Rio dos Sinos (Unisinos) and Master in Environment Resources Management from Vrije University, The Netherlands. With participatory video experience in 25 countries, she co-designed and facilitated the participatory video project for UN/IOM Global Migration Film Festival.

Contact: fernanda.baumhardt@commswithcommunities.com

\section{Abstract}

From August 2017 to September 2018, IOM, the UN Migration agency experimented for the first time, participatory video methodology integrated in the activities of its Global Migration Film Festival. The purpose was to innovate and enable communities in the frontlines of displacement at different humanitarian action settings into filming their own stories and narratives with their own hands and styles. Their films would then integrated a film festival that traditionally curate films professionally produced with specialized film crew, based on script and focus quality and esthetics. Amongst the six countries and areas with displaced population that received the activities is Roraima, Brazil that has been hosting thousands of Venezuelans that left the country due to the degrading living conditions. In May 2018 the authors spent a week at Pintolandia Indigenous shelter in Boa Vista, facilitating a group of 25 displaced Venezuelans of the ethical groups of Warao and Enepas to make their films that would raise and disseminate their voices around the world. Additionally, the facilitators would observe the potential benefits of the method to generate some level of social cohesion and integration between the participating displaced communities and it's hosting environment. This article utilized simple and direct language, similar to the conversations on the ground, in the frontlines of human displacement.

\section{Keywords}


Participatory Video, social cohesion, film festival, indigenous displaced population, Venezuela.

\section{Summary}

1. Introduction/ Project Background

1.1 Displacement and the Global Migration Film Festival as a platform to raise awareness

1.2 Participatory video methodology: an innovative approach integrating the UN Migration film festival

1.3 Participatory video in the context of people-centered humanitarian action

2. Participatory video with displaced indigenous Venezuelans in Brazil

2.1 A brief narrative of the process

2.2 Participatory Video Screenings and dissemination at UN platforms

2.3 Engaging the Federal University of Roraima Communication Students

2.4 The PV process in steps

2.5 Feedback from the participants on the PV process

3. Lessons Learned and Recommendations

4. Conclusion 


\section{INTRODUCTION/PROJECT BACKGROUND}

\subsection{DISPLACEMENT AND THE GLOBAL MIGRATION FILM FESTIVAL AS A PLATFORM TO RAISE AWARENESS}

Forced migration is on the high. The number of forcibly displaced people rose from 59.5 million in 2014 to 70.8 .5 million in 2018 (OCHA, 2019). In this context, humanitarian actors have been increasing their efforts on advocacy towards policy makers and donors pledging further investment and compliance to international law that could dismantle many of the root causes and impact of forced displacement. Equally important, is the need to inform and educate the general audience on humanitarian principles and rights around migrants and refugees to prevent the rise and the spread of xenophobia and violation of human rights. The Regional Refugee and Migrant Response Plan for Refugees and Migrants from Venezuela lead by UNHCR and IOM aims to provide some kind of assistance to the 4,486,860 Venezuelan migrants, refugees and asylum-seekers (R4V Platform 2019) spread around the continent, launched an awareness campaign in multiples countries of Latin America "in an effort to curb xenophobia against Venezuelans and promote solidarity" (UNHCR, 2018).

In early 2016, The Global Migration Film Festival (GMFF) was born with a different twist: to widely disseminate films and documentaries that capture "the promises and challenges of migration," The goal of the festival is "to pave the way for greater discussion around one of the greatest phenomena of our time: migration." (IOM, 2017). It stands on the belief that:

Films can cultivate deeper empathy for migrants and a better understanding of their realities, needs, perspectives and capacities, using films as educational tools to influence perceptions of and attitudes towards migrants, by bringing attention to social issues and creating safe spaces for respectful debate and interaction." (IOM, 2017)

The author and researcher Kendall Haven authored a book that compiled much of the evidence collected in decades of work proofing how storytelling affects our brain and emotions. In one of the chapters he writes about research carried out by cognitive scientists that have demonstrated that "experiences not framed into story form suffer loss in memory" (Mandler \& Johnson, 1977). "We remember stories better and longer than the same information presented in any other narrative form." He describes that a Senior Official from the World Bank used storytelling "to persuade executives to get enthusiastic about a major change." (Haven \& Ducey, 2007). Hollywood has become an incredible profitable business just by exploring the art of storytelling and narratives that hook audiences around the world. Therefore, why not further apply it for the good causes of the humanitarian world?

\subsection{PARTICIPATORY VIDEO METHODOLOGY: AN INNOVATIVE APPROACH INTEGRATING THE UNITED NATIONS (UN) INTERNATIONAL ORGANIZATION FOR MIGRATION FILM FESTIVAL (IOM)}

In 2017, the second edition of the Global Migration Film Festival took an innovative approach and launched an initiative to directly engaged communities in the frontlines of migration on storytelling through participatory filmmaking. The aim was to help groups of displaced populations and affected community to direct and document their own narratives without being directed and produced by professional filmmakers and observe if during the collective process, social cohesion could be straightened. From September 2017 to August 2018, six Participatory Video (PV) projects were conducted in Jordan, South Sudan, Switzerland, Brazil/Venezuela border, Madagascar and Afghanistan. The profiles of the participants were diverse regarding gender, age, education level and background. Many fled their home to search of protection and economic stability, others to reunite with their families or to escape the growing impacts of climate change. In total, 85 community members of 22 nationalities and six ethinies speaking 15 languages were engaged in participatory video, producing over 12 hours of footage that gave origin to 6 participatory films edited by them.

To come to the encounter of these communities, 17 IOM Missions and partnering institutions were involved, funded by the IOM Development Fund (IDF). The Norwegian Refugee Council NORCAP Roster - global provider of humanitarian expertise - supported with technical capacity by deploying the PV facilitator, co-author of this article, that along with the festival's coordinator codesigned and co-lead the PV activities in every country. It is important to note that this pool of "traditional" actors were for the first time collaboratively experimenting a non-traditional bottom-up filmmaking methodology combined with a set of Communications with Communities 
(CwC) techniques. The initiative offered an added value to the IOM Country Missions involved that acted as access gates to the displaced communities. During the intervention, the PV team also provided support to certain organisation's programmes by training local staff on new communication approaches and photojournalism in the humanitarian and development context.

With this framework, the festival expanded its horizons and lenses that typically focuses on disseminating narratives. It recognized migrants and affected communities beyond a passive subject to empower them to be authors and producers of their very own stories.

\subsection{PARTICIPATORY VIDEO IN THE CONTEXT OF PEOPLE-CENTERED HUMANITARIAN ACTION}

Before advancing to describing one segment of this experience, its relevant to refer back and examine the origins of Participatory Video as it has formed the argument of electing this methodology to integrate a traditional film festival: The Challenge for Change, a participatory film and video project created in 1967 by the National Film Board of Canada and its key aspect of "transferring of control over the filmmaking process from professional filmmakers to community members so that ordinary Canadians in underrepresented communities could tell their own stories on screen. Community dialogue and government responses to the issues were crucial to the program and took precedence over the "quality" of the films produced" (Schugurensky, 2005). The subsequent Fogo Process, lead by D. Snowden of Memorial University of Newfoundland and C. Low worked with fishing communities on conflict resolution through film dialogues (Snowden, 1984). Traditional filmmaking roles were reversed, 'object audience' became 'subject participants' in the message. It nurtured a shift in the power, as the narrative power was transferred from the filmmakers to the community itself (Lewis, 1977). Don Snowden, the filmmaker and researcher leading The Fogo Process later reflected on the outcome:

Today few people on Fogo speak often about the filming, yet many believe their lives were changed enormously by it. This can never be accurately measured. But it is certain that the fishermen formed an island-wide producer's cooperative which handled and processed large catches, enabling them to keep the profits on their island. Unemployment of able-bodied men disappeared, and government directed their efforts to helping people stay... Films did not do these things: people did them. There is little doubt, however, that film created an awareness and self-confidence that was needed for people- advocated development to occur. (Snowden, 1984).

Despite the fact that the Fogo Island project has sparked the concept of using filmmaking in a participatory way and that it has proven its potential in fostering participatory communication, (White, 2003), traditional video practices have dominated the international development sector in the following decades. Meaning that filmmaking have been primarily utilized as a tool to technically capture and deliver messages and stories without the element of horizontality. Recently, a diversity of researchers and practitioners associated with the humanitarian and development sectors are progressively looking into approaches that "give voice to the voiceless" (Schugurensky, 2005) at the grassroots level, changing the old perspective where of communities were merely passive recipients of vertical information (Baú, 2014).

The importance of this rather new way of thinking and potential workstream, of engaging and empowering affected communities in preventing and responding to crisis and disasters were intensively addressed at the Agenda for Humanity1. In one of its key outcomes - The Grand Bargain, endorsed by 61 donors and aid organisations calls for a "people-centered" humanitarian responses. It's goal number six appeals for "a Participation Revolution: to include people receiving aid in making decisions which affect their lives." (Agenda for Humanity, 2016).

However, in order to be people-centered and institutionalise a genuine participatory approach or moreover, a new modus operandus, vulnerable and affected communities are no longer to be labeled 'victims', 'recipients' or 'beneficiaries' but "dynamic social actors with capacities and ideas of their own who are able to take an active role in decisions affecting their safety and welfare." (Groupe Urgence Réhabilitation Développement, 1994). Moreover Brown, Donini and Knox (2014) argue that it is not only engagement but high community-engagement that should be pursued by humanitarian actors, which can only be achieved with participation and ownership. Aid agencies are still struggling to institutionalize and scale-up common feedback mechanisms that heavily rely on tools that are either obsolete, such as feedback boxes, unknown or inaccessible by the affected communities. That is to say that more advanced and 
highly engagement participatory methods may take decades to get off the ground in an industry that perceives Focus Groups Discussions as participatory. On an attempt "to ensure more accountable humanitarian operations", in 2015 the UN Office for Humanitarians Affairs (OCHA) and coordination body launched the "living document" "Effective Coordination: placing people at the centre of humanitarian responses' bringing "suggested actions and ideas to OCHA staff to improve Accountability to Affected People (AAP) in coordination mechanisms and throughout the humanitarian programme cycle. In the publication, Community Engagement is defined as "a programmatic field of work through which humanitarian organisations can be accountable. It includes three operational components: feedback/complaints, participation, and information provision. The term "communicating with communities" or CwC is also used for this work. However, "community engagement" is now a preferred term for many organizations, as it implies a more active process which should sit with programming and not only with "communications" or "public information" teams." (OCHA, 2019)

In 2001, 14 years before these discussions around community engagement and participation gained space and momentum in the humanitarian sector, Gumucio described, the role of "The New Communicator for social change": "in communication for social change the process is more important than the products. In journalism, the articles, the video documentaries, or de radio programs are valuable results for a skilled professional. But in social change and development, the process of communication with the people and within communities is more important than the printed or audiovisual aids that may emerge from that dynamic. Is in the process of communication and participation that social change starts to happen." (Gumucio Dragon, 2001)

Applied into the practice of Participatory Video, the idea of empowerment combines the concept of action and intervention. It is important to keep in mind that to be empowered means to create a certain level of political conscientization (Montero \& Moreno Domínguez, 2014). To empower means to enhance the freedom of an individual or community through increasing their knowledge about issues, about choices and alternatives. It speaks to increasing their capacity to identify opportunities and recognising the need to go further and differently. When knowledge about problems, strengths and alternatives is stimulated, it triggers the process of empowerment which is not immediate and static, it is a continuous evolving, adapting and discovering process without a delimited end. Community empowerment requires a balance between extending opportunities to have a voice and, at the same time, to and foster efficiency in community functioning. Ideally, the design and use of empowerment activities and technologies in the humanitarian and development sector should foster the dignity and respect that can come with self-determination. (Fawcett et al., 1983)

Participatory Video method is a popular alternative and collective practice which aims empowerment through the process of social appropriation of the audio-visual technologies where communities are the active creators of a message or story. (Montero \& Moreno Domínguez, 2014). As Shaw and Robertson wrote: "Participation implies the idea of active engagement. To do, to go, to lead instead of to observe, to receive, to be led". They also argue that as a result of participation empowerment will be strengthened as it "implies that people and communities take the lead and are responsible and accountable for their own lives Empowerment is protagonism combined with selfdetermination to transform their own situations." (Shaw \& Robertson, 1997). Nevertheless, an important element of participation is establishing relationships between different people or groups encouraging allowing mutual understanding and trust to be built (or re-built). It helps empathy to be developed encouraging the involved people to consider other's ideas and needs supporting consequently the construction (or reconstruction) of social-cohesion. Social cohesion often refers to common values and purpose in a society, including a sense of belonging and solidarity for people from diverse backgrounds. (Cheong et al., 2007) Participation in, and identification with, social practices are central to social integration and cohesion, where instead of having isolated groups at risk of conflict amongst themselves there is a public sphere where active citizens share and shape public places. (Jansen, Chioncel \& Dekkers, 2006)

\section{PARTICIPATORY VIDEO WITH DISPLACED INDIGENOUS VENEZUELANS IN BRAZIL}

In May 2018 the authors and PV facilitators arrived in Boa Vista, Roraima, north of Brazil to carry out a participatory video process with Venezuelan indigenous migrants living in Pintolandia, 
a shelter established to host exclusively indigenous people from Venezuela. At the time, over 700 Venezuelan indigenous migrants of two ethinies, Warao and Eñepas, were living in Pintoladia. These indigenous people were affected by the humanitarian crisis in Venezuela and have left the country in search of basic needs such as food and medicine. At the time, the State of Roraima had registered the highest number of Venezuelans who have entered Brazil. According to the Brazilian Government, by April 2018 more than 40,000 Venezuelans had applied for the regularization of their migration status in the country. The GMFF PV project and activities were aligned with IOM Brazil's specific lines of work: 1 . Integration; 2. Strengthen community capacity in camps in organization and leadership.

Originally the participatory video project intended to work with a group of Warao people. After the facilitators made their first visit to the shelter and discussed with the local organizations and authorities working at the facility, they were informed about a second indigenous ethnicity living in the indigenous shelter: the Eñepas, a minority making about $10 \%$ of the hosted population. It became clear the need to adjust planning and extend the work to include the Eñepas, otherwise unintentionally the PV facilitators could have reinforced potential existing disparities. According to Emerson Rodrigues, an experienced anthropologist working at Pintolândia then, Eñepas and Waraos don't interact much amongst themselves. As the Eñepas were a minority and their nature is more reserved, it was difficult to engage with them. Consequently, they were somehow marginalized. Taking this context into consideration the project had to be reorganized and adapted to incorporate two participatory video processes instead of one, in a very limited time. Instead of doing a four days training with the Waraos, this time frame had to be split between the two groups. The activities were adapted to the new reality and the facilitators worked with both groups totalling 20 people - 12 Waraos and 8 Eñepas. One of the aims was to empower and amplify the voices of the two different ethnic groups and communities living in the shelter, and through this dialogue, tentatively strengthen social cohesion between the two migrant communities.

\subsection{A BRIEF NARRATIVE OF THE PROCESS}

This session aims in a simple and direct language, such as spoken on the ground, to recap the participatory video processes, highlight passages that stood out and share some of the lessons collected from the field. The process of writing was challenging as it happened in parts during and many months after. The authors apologise in advance for the flaws and narrative style. They did their best writing it mostly while carrying on other projects.

The overall profile of the two groups was quite diverse: there were young leaders, female and male adults as well as womens' elders. Many children watched the activities while playing nearby. The training activities stimulated peer-to-peer capacity building on a horizontal and upwards spiral way. The foundation of any PV process is trust, firstly within each individual "I trust I can do it", then within the collective group - "We trust we can do it" - then between them and the facilitators - "we trust they can help us do it".

One key aspect of trust is communication. The language spoken was Spanish with a few members speaking their indigenous languages. The fact the facilitators spoke both Spanish and Portuguese, helped trust building and avoided the intermediation and layer of translators. To facilitate a PV in local language makes a significant difference on the speed and depth of the engagement and influences both the flow and results.

The dynamics were fluid, meaning that participants felt free to come and go adhering according to their own pace and availability that depended mostly on the day's routines and unexpected situations. Women had to cook and take care of their children. Some attended while breastfeeding. The cacique ${ }^{10}$ frequently had to leave to attend community meetings and food distributions. The training space was open and inclusive as members of the shelter community not enrolled in the PV training also participated by observing the activity and sometimes giving their inputs and support to the PV learners. Local government authorities representatives eventually passed by to observe the activities, including militaries that were in charge of the shelter order and security. The facilitators acted at the same time as diplomats and gate keepers to preserve both trust of the community as well as the authorities that allowed the activity to happen. 
Through games and exercises, they learned how to operate the video camera by focusing on the basic commands: record, stop and zoom in and out. The facilitators introduced the hand microphone only after all the participants had experimented with the video camera, and felt they were somehow mastering it. The hand microphone has a profound meaning which goes beyond that "I have a voice". It's about holding it, standing with and therefore "owning my voice". The first exercise with the microphone is "Who Am I", in the broader sense and as deep as the participants allow themselves to go.

One elder lady that held the camera and microphone for the first time in the lives laughed and told the group "look how beautiful I am!" The atmosphere had a sense of pride in who they were, in their very essence, despite the fact they were now displaced from the communities of origin and were living inside the walls of a shelter in a foreign land. A group of ladies started singing traditional songs and brought their traditional clothes and art craft "to show to the whole world our culture." Clearly the most significant moments observed by the facilitators were when the indigenous participants touched the camera for the first time and when they watched themselves on the computer screen.

Only after experimenting the video tools and realizing what the tools can do in terms of amplifying their voices and projecting their images and mainly how they self-represent themselves, we moved to the content discussion. In group, they discussed and listed what they would like to talk about in their film, what messages they would like to transmit, how they would like to represent themselves. In harmonious consensus, both groups wanted to talk about themselves as indigenous communities: "This is our film and we would like to present ourselves just as we are."

They discussed and voted the theme and stories they were going to film to share inside and outside the shelter walls. They clearly wanted to show their reality of being in a shelter as displaced communities but opted to extend that narrative beyond displacement and into their traditions. They filmed dances, artwork, stories and traditional knowledge transmitted by elders and talked about their food. All the scenes were filmed with the same background: the shelter white walls.

After completing the process with the group of Warao people, the team facilitated the same process with the Eñepas people. Their group was smaller - initially only five participants joined.
However the number increased as their fellows noticed the work involved cameras. The group took longer to understand and engage in the activity, as indicated by the anthropologist working in the shelter that could happen. To help build trust and start engagement, the PV team showed photos of the Warao PV process in a very calm and slow pace, letting them watch carefully. As they did, they exchanged a few words in their local language amongst themselves. The intention with this technique was not to compare but to help the Eñepas participants visualize the stages of the activity and start developing. Their cacique, a young men, had a prominent voice and only after he understood the activity better, he gave the green light to the group, in a subtle body language and code.

After a slower pace start, they swiftly engage and started filming their messages and stories mixing the stages of experimenting with the video camera and microphone with discussing and filming their stories. It was all blended in one organic and non-structured PV process. The facilitators stepped back giving them the space to create and experiment in their best rhythm and sequence. She stepped in after every participant had recorded enough material. It was important to pause and watch themselves. Similar to the Waraos process, when they see their images and hear their voices, self-recognition triggers self-respect that generates a sense of pride: "we are the Enepas." There was a consensus within the group that the content was good enough for their video. They recorded the closing message in the form of a song sung by a young men, not older than 18 , that had a nostalgic look on his face as he sang about their indigenous village back in Venezuela.

The two videos were edited by the facilitators with the two groups. This stage of the process was also fluid, starting with only a few participants due to the busy daily routines. We started by reviewing and editing the footage per interviewee. This method worked well as it was adjusted to their reality. They called each other that it was time for that person to review his or her footage and select "their voice". As the day progressed, more participants arrived and at one point the group was complete. Together they reviewed the edited video and gave feedback on the final product. They seemed happy with the result and were laughing and chatting with each other as they watched themselves in an organized sequence on the screen. They discussed and chose the title for their videos and showed excitement about the upcoming screening. They were proud of what they did and who they are. 


\subsection{PARTICIPATORY VIDEO SCREENINGS AND DISSEMINATION AT UN PLATFORMS}

After the videos have been edited with the participants of the two groups, the project moved to the final and important stage: presenting it locally and disseminating it globally. The first and most important video screening happens at the community level and this was organized at the very indigenous shelter two days after the videos were finalized. It was mid morning on a weekday and the camp screening, that was informed by word of mouth, attracted a large local audience. Three hundred people gathered in the main maca room "redário" at Pintolandia Shelter, including the indigenous community, local authorities, NGOs representatives and guests. The event was organized by the local IOM office. The main white wall of the room was used as a screen and their movies were played by a projector connected to a laptop and external audio system with a microphone. There were three participatory videos projected. An artistic opening with a sequence of close-up image of the eyes of each indigenous participant preceding by the title they have selected: Somos Un (We Are One). After the common opening, the Enepas participatory video was presented followed by the Waraos participatory video. The audience enthusiastically applauded the session and started chanting "one more time, one more time...", so the videos were presented again. The children had their eyes glued to the screen and the room was silent with only a few laughs here and there.

Many conversations about the experience of indigenous people making a video and watching themselves on a big screen of a shelter cinema with fellow community members as main audience could be observed around the room. Madga Azevedo, a representative from the Labor and Social Welfare Secretary's office - the governmental entity managing Pintolândia shelter observed the process and said it had collaborated to strengthen the integration of the two indigenous groups living in the same space: "I felt emotional with their reactions watching their own videos. It was about empowerment and selfrecognition."

After this first community event, additional screenings were organized in Boa Vista by IOM local team. One specifically for human-rights and migration specialists when the very own indigenous participants presented their film and participated in a debate after the session. The second was during the 3rd edition of the Global Migration Film Festival in Boa Vista that happened at the Federal University of Roraima (UFRR) and targeted academics, university students and guests.

The participatory videos were published at the United Nations Brazil official website that highlighted the videos on their front page. They were also published at the Global Migration Film Festival website that had a dedicated section for the Participatory Video Project as well as the Festival Vimeo channel.

IOM also drafted a special Press Brief Note (PBN) highlighting the process and videos produced by the displaced indigenous people hosted at Pintolandia shelter in Brazil. The piece included the video links and was disseminated to journalists and media outlets around the world.

\subsection{ENGAGING THE FEDERAL UNIVERSITY OF RORAIMA COMMUNICATION STUDENTS}

The two PV facilitators were invited to give a special lecture at the Federal University of Roraima to the students of Social Communication Journalism and International Relations. The purpose was to transfer knowledge and experience on Humanitarian CCommunications, a discipline that is new in Brazil, and also the opportunity to raise awareness of issues around displacement and migration. The theme was 'Photography and Participatory Video in Humanitarian Crisis' and it introduced the different aspects of bottom-up and community oriented approach to communications that is peoplecentered and not agency-visibility-focused..

The overall feedback received from the professors involved in the organization and the attending students was very positive. Professor Lisiane Aguiar, coordinator of the discipline of Photo-journalism stated that the lecture had introduced a new world to the students. Due to the positive feedback from students, the University invited the team to give a second lecture. Approximately one hundred people received the learning. It is important to note the context in which this University intervention happened. The capital Boa Vista and whole of Roraima state had been highly impacted by the influx of Venezuelan migrant. Therefore, it was an important action to raise awareness of humanitarian principles, migrants rights and the need to respect their dignity. The Journalism students were particularly interested in both subjects: humanitarian photography and participatory video and 
many followed up with the facilitators asking for advice on ways to contribute to the sector.

\subsection{THE PV PROCESS IN STEPS - SEQUENCE APPLIED WITH THE WARAO GROUP}

1. Introductions: participants present themselves followed by the facilitators that explain the project visually, through images of previous PV processes illustrating the steps of the activities.

2. Icebreaker: with a thread the group weaves the human web to inspire the collective work.

3. Discover the equipment the group sit in a circle and equipment bag is placed in the middle. In an unstructured sequence, participants discover what is inside the bag. They explore together the video camera as the simple commands are given by the facilitators.

4. Learning to speak in front of the camera: with a hand-microphone they start by the "Who am I" exercise. Next Explore playing a reporter and interview their peers.

5. Watching and learning: participants watch together their first recordings and learn by observing and critically discussing what is good and what can be improved.

6. Group discussions on content: different exercises to inspire the group define their topic and editorial line, which stories they would like to film and who will tell them.

7. Filming their stories: working in small production teams (usually 1 camera, 1 reporter and 1 interviewee), they start filming the content agreed on the previous step.

8. Participatory Editing: with the technical support of the facilitators, participants review the footage and select the content. They also order the edited video clips in their most preferred sequence. At the end of the editing, facilitators consult if they would like the videos to be disseminated externally in other screenings and social media platforms. In the case of both groups, $100 \%$ of the participants confirmed that they would like to have their videos widely disseminated, locally and globally.

9. Community screening: a local screening is organized with the participants to present their film to the whole shelter community. At the end of the screening copies of the final videos and photos are delivered to the participants.
10. Participants feedback on the process: after the screening, the PV team collects feedback through a simple survey and video testimonials.

11. External screenings and dissemination.

\subsection{FEEDBACK FROM THE PARTICIPANTS ON THE PV PROCESS}

The aims of collecting feedback from the participants on the activity was:

1. To provide communities a channel to express reactions and inputs;

2. Facilitators, project managers and donors to review the experience from the community's point of view;

3. Learn with the experience. Immediately after the video screening, the feedback was collected using the following methods:

A short and anonymous survey, with closed and open-ended questions distributed to all the participants

Video interviews done randomly with a small sample of participants with three open questions.

The results were compiled and analysed by the team. The information and learnings integrated the final project report.

Feedback received by 17 participants

Survey questions - answers received:

1. Describe in one word how do you feel after making this film:

Proud and empowered. Yes I can do it. I can film and I can speak.

Very happy and very touched.

I was nervous and I think we can get better.

I learned how to film. I never thought we the Warao people could make a film like that. I liked it very much.

I feel very happy. It was the first time I was on a video. Thank you and congratulations to all of us.

I am very happy. I liked the video very much and I feel motivated.

I am proud with the result and happy to have been invited.

I liked very much and I would like to learn more.

I am very happy because I am in the video. 
Beautiful. I see myself beautifully in the video along with my fellow friends.

I feel good and happy.

I feel happy and calm because we told our story from our Venezuela.

2. What did you most like about this process?

The participation of everyone.

Working as a group.

Working as a group and making a film together.

What I most liked was working and sharing with my fellow community members.I spoke very well and I liked watching myself on the big screen asking for work.

I liked operating the camera.

I liked everything.

I like participating and also speaking and singing.

I liked very much the two videos, from the Enepas and the Waraos.

What I mostly liked was to do our traditional dance.

I liked showing what I have in my mind. My story.

I liked that it was made by us.

I liked very much as we looked at two themes: the waraos and the enepas. It was like having a big meeting between the two indigenous groups and we have never seen this before. This was wonderful.

3. Do you have any recommendations to the facilitators?

I would like to continue making videos showing our traditions.

Film more voices

Do another participatory video training

Film more voices

Film more about our customs and traditions

Make another video to learn more

Film more voices

Film more voices

Participate in another video

I learned a lot

We should make another video

Fim more voices
4. What did you learn in terms of human interaction?

Yes I learned something. Next time I would like to do it better.

Yes I think the group did very well. We were all good communicators answering the questions very well and interviewing as well.

I realize that together we can go farther. We can do much more.

I learned about the other ethny, the Enepas.

I liked that we shared our traditions and knowledge with others.

5. What did you learn about the other indigenous group? Does the video process help strengthen the dialogue between the two ethnies?

Yes I learned with the Enepas video about their traditions and way of living. It is very similar to ours (from Waraou Cacique). Yes I believe so. Now we can exchange our knowledge in person as well. I think that will happen.

Yes I learned what they make as craft work, some is similar to what we make.

Yes I learned a bit about their culture and their traditional music.

No I did not learn much.

I learned about the Enepas, how their ancestors lived with the arch and also about their craft work.

I learned about the traditional dances of Warao people.

I learned that the Enepas also have typical food just like the Waraos.

No.

No.

Yes I learned how they cultivate. It is very similar than how we the Waraos do it. It was excellent.

Three out of the ten participants affirmed that they did not learn with the other group. Seven participants confirmed they have learned something about the other ethnie.

The answer number 1 , given by the Cacique Warao, stated "Now we can exchange our knowledge in person as well. I think that will happen" indicates how the screening of the films to both ethnies together at the same time created a sense of recognition of the other, recognition of the value and similarities of other knowledge and culture. Recognizing commonalities between themselves can spark social cohesion: 
I enjoyed that we watched the two different films: the Waraos and the Eñepas. This was incredible. We have never looked at ourselves like this, through a video camera. It was like a big meeting between the two ethnicities living here. Feedback given in video interview by Baudilio Centeno, Warao participant.

During the screening, I liked watching both videos: the one made by the Eñepas and the other made by the Waraos. I also enjoyed that they were made by us. Feedback recorced spontaneously by a member of the audience

\section{LESSONS LEARNED AND RECOMMENDATIONS}

Several lessons were learned throughout the project, not restricted to the experience with the displaced indigenous Venezuelans.

Limitation: One single PV activity in a context that requires far more extended work. Participatory Video to be integrated at long-term development and humanitarian programs.

Insufficient allocated time - for all the steps of the activityAt least five days should be dedicated for each group. The project time assigned was insufficient to reach the full potential of the methodology. Additionally, more time is required for observing the context and participants profile, to understand dynamics before engaging the displaced community in the activity. More time is also recommended to plan and organize additional screenings.

Challenging training space with high background noise, including construction machines, loud music and children playing loud that generated in the participants and facilitators dispersion and lose of focus.

Restricted filming space as it was forbidden to film inside the shelter premises. The training was constrained to a medium size tent with no possibilities for creative filming and storytelling.

Eñepas did not speak Spanish fluently and as there was not a translator available to support the activity. Participants would take longer to understand the process and were limited in expressing themselves and communicating directly with facilitators. Eñepas were also shy and more introspective than Waraos and it took longer for them to confidently engage with full potential.

The very nature of the displacement situation with its accumulated traumas and pain, uncertainty and struggle for survival. On the other hand, the light and fun atmosphere offered participants some moments of relief from the ordinary daily preoccupations;

The external PV facilitator perceived that the participatory videos produced by the communities did not attract the same level of interest from the different IOM Country Offices when curating and selecting the films to the Festival line ups. IOM's Global Migration Film Festival was originally designed to highlight professionally produced films made by professional and emerging producers and filmmakers, in the contrary for participatory videos that are produced by communities, without a script, no resources and focused on process not final product. The videos produced by the communities at a certain extent were more interesting and adequate to the local audience. Nevertheless it was a positive experience, to introduce the approach and methodology at Film Festival which was designed as a platform to promote professionally made filmsf. It can serve as an example of innovation and intersection, not convergence, of a traditional top-down communication strategy and bottom-up participatory communication process and product.

It can be challenging for traditional communicators, who are trained to direct, script and produce the content themselves, to understand and fully embrace a participatory communication approach. Frequently, they resist in giving communities the editorial control. The external PV facilitator had to dedicate additional and specific time other than working with the communities, to guide and explain every step of the methodology to the Communications Officer involved. Not an easy task that can be overwhelming as the very nature of the project is expected to be fully accepted before implementation.

\section{CONCLUSION}

IOM (UN Migration) Global Migration Film Festival Participatory Video Project has the potential to empower and develop communities's capacities in communications and filmmaking. Ultimately it is a process that can catalyse social change by self-reflection, selfrecognition, self -and-collective-value, protagonism and participation. However, it is not clear to what extent it can strengthen communities' resilience, social cohesion and integration, especially considering the parachuting nature of a one time activity done with multiple limitations 
in a complex context and environment. Some of the questions that remain within the authors and facilitators that require further analyses and investigation:

How do we move from a one time activity to integrating the multiple applications of PV methodology to support humanitarian programmes?

Is it realistic to assure community editorial freedom when operating from within the humanitarian system that is increasingly becoming more political?

How do we balance and find a common ground between raising displaced populations voices and challenging realities through their very own perspectives and narratives with the sensitivities related to the host government and leading humanitarian actors that have states as members of their organization?

Which battles are worth fighting? Who can get burned in the process of protecting the displaced communities freedom of expression?

Is it feasible and realistic to integrate participatory approaches in sensitive humanitarian contexts when implementing from within the humanitarian system that is a partner of the hosting government?

So much effort to enable and raise displaced populations voices from within, then what?

\section{BIBLIOGRAPHIC REFERENCES}

- Agenda for Humanity 2016. (2016). Political leadership to prevent and end conflicts. Retrieved from: https://agendaforhumanity.org/cr/1/\#1D.

- Baú, V. (2014). Telling stories of war through the screen. Participatory video approaches and practice for peace in conflict-affected contexts. Conflict \& Communication, 13(1). Retrieved from: http://www.cco.regeneronline.de/2014_1/pdf/ba\%C3\%BA.pdf.

- Brown, D., Donini, A. and Knox, P. (2014). Engagement of crisis-affected people in humanitarian action. ALNAP's. 29th Annual Meeting, 11-12 March 2014, Addis Ababa. London: ALNAP/ODI. Retrieved from:

https://www.researchgate.net/profile/Paul_Knox_ Clarke2/publication/270586187_Engagement_of_c risis-

affected_people_in_humanitarian_action/links/54a fb37f0cf29661a3d5d0af/Engagement-of-crisisaffected-people-in-humanitarian-action.pdf.
- Cheong, P.H., Edwards, R., Goulbourne, H., Solomos, J. (2007). Immigration, social cohesion and social capital: a critical review. Sage journals. doi: 10.1177/0261018307072206.

- Fawcett, S. B., Seekins, T., Whang P.L., Muiu, C., Suárez de Balcazar, Y. (1983). Creating and using social technologies for community empowerment Prev Hum Serv, 3 (2-3), pp. 145-171. doi: 10.1300/j293v03n02_08.

- Gumucio Dragon, A. (2001). The new communicator. Retrieved from: https://www.researchgate.net/profile/Alfonso_Gu mucio/publication/265429874_The_New_Commu nicator/links/54b3cb240cf2318f0f95f038.pdf.

- Groupe Urgence Réhabilitation Développement. (1994). 'Chapter 1: Participation? What? Why?Who? How?', Participation Handbook for Humanitarian Field Workers. Involving CrisisAffected People in a Humantarian Response, (chapter 2), pp. 23-44. Retrieved from: www.urd.org.

- Haven, K. F. \& Ducey, M. (2007). Crash Course in Storytelling. Santa Bárbara: Greenwood Publishing Group.

- IOM (2017). Global Migration Film Festival. Iom.int. Retrieved from: https://www.iom.int/global-migration-filmfestival/gmff/official-selection/es/fr/fr/centresadministratifs.

- Jansen, T., Chioncel, N. \& Dekkers, H. (2006). Social cohesion and integration: Learning active citizenship, British Journal of Sociology of Education, 27(2), 189-205. doi: $10.1080 / 01425690600556305$.

- Lewis, P. (1977) Video in non-formal education- $A$ bibliographical study. Paris: Unesco - Division of Structions, Contents, Methods and Techniques. Retrieved from:

http://unesdoc.unesco.org/images/0002/000248/ 024897eb.pdf.

- Mandler, J. \& Johnson, N. (1977). Remembrance of things parsed: Story structure and recall. Cognitive Psychology - COG PSYCHOL, 9, 111-151. doi: 10.1016/0010-0285(77)90006-8.

- Montero, D. y Domínguez, J.M.M. (2014). El cambio social a través de las imágenes: guía para entender y utilizar el vídeo participativo. Madrid: Los Libros de la Catarata.

- Mortensen, M., Allan, S. and Peters, C. (2017). The Iconic Image in a Digital Age. Nordicom Review, 38 (s2), 71-86. doi: 10.1515/nor-2017-0415.

- OCHA (2019) US\$21.9 billion needed in 2019 as average length of humanitarian crises climbs. Retrieved from:

https://www.unocha.org/story/us219-billion- 
needed-2019-average-length-humanitarian-crisesclimbs

- Phillips, D. (2018) Brazil calls in army after mob attacks on Venezuelan migrants. The Guardian. Retrieved from:

https://www.theguardian.com/world/2018/sep/0 2 /brazil-army-venezuela-border-migrant-crisisattacks.

- Schugurensky, D. (2005). Challenge for Change launched, a participatory media approach to citizenship education. The Ontario Institute for Studies in Education of the University of Toronto (OISE/UT).

- Shaw, J. \& Robertson, C. (1997). Participatory Video: A Practical Approach to Using Video Creatively in Group Development Work. London: Routledge.

- Snowden, D. (1984). Eyes See, Ears Hear. Memorial University. Retrieved from:

https://www.participatorymethods.org/sites/part icipatorymethods.org/files/eyes $\% 20$ see $\% 20$ ears $\%$ 20hear_snowdon.pdf.

- Teitelbaum, K., Horton, M., Friere, P., Bell, B., Gaventa, J., \& Peters, J. (1992). We Make the Road by Walking: Conversations on Education and Social Change. History Of Education Quarterly, 32 (1), 146-148. doi: 10.2307/368424.

- UNHCR (2018). Venezuela Situation. Retrieved from:

https://data2.unhcr.org/en/documents/download /63883.

- UNICEF (2017). Putting People at the Centre of Humanitarian Action [Ebook]. UNICEF.

- White, S. A. (2003). Participatory video: images that transform and Empower. Thousand Oaks: Sage. 